\title{
Ketamine for Social Anxiety Disorder: A Randomized, Placebo-Controlled Crossover Trial
}

\author{
Jerome H Taylor, ${ }^{*, 2,3,}$, Angeli Landeros-Weisenberger', Catherine Coughlin', Jilian Mulqueen', \\ Jessica A Johnson', Daniel Gabriel', Margot O Reed', Ewgeni Jakubovski' and Michael H Bloch',2 \\ 'Child Study Center, Yale University, New Haven, CT, USA; ${ }^{2}$ Department of Psychiatry, Yale University, New Haven, CT, USA; ${ }^{3}$ Department of \\ Psychiatry, University of Pennsylvania, Philadelphia, PA, USA
}

\begin{abstract}
Many patients with social anxiety disorder (SAD) experience inadequate symptom relief from available treatments. Ketamine is a potent $\mathrm{N}$ methyl-D-aspartate receptor antagonist with a potentially novel mechanism of action for the treatment of anxiety disorders. Therefore, we conducted a double-blind, randomized, placebo-controlled crossover trial in 18 adults with DSM-5 SAD and compared the effects between intravenous ketamine $(0.5 \mathrm{mg} / \mathrm{kg}$ over $40 \mathrm{~min}$ ) and placebo (normal saline) on social phobia symptoms. Ketamine and placebo infusions were administered in a random order with a 28-day washout period between infusions. Ratings of anxiety were assessed 3-h post-infusion and followed for 14 days. We used linear mixed models to assess the impact of ketamine and placebo on anxiety symptoms. Outcomes were blinded ratings on the Liebowitz Social Anxiety Scale (LSAS) and self-reported anxiety on a visual analog scale (VAS-Anxiety). We also used the Wilcoxon signed-rank test to compare the proportion of treatment responders. Based on prior studies, we defined response as a greater than 35\% LSAS reduction and 50\% VAS-Anxiety reduction. We found ketamine resulted in a significantly greater reduction in anxiety relative to placebo on the LSAS (Time $\times$ Treatment: $F_{9,115}=2.6, p=0.01$ ) but not the VAS-Anxiety (Time $\times$ Treatment: $\left.F_{|0,14|}=0.4, p=0.95\right)$. Participants were significantly more likely to exhibit a treatment response after ketamine infusion relative to placebo in the first 2 weeks following infusion measured on the LSAS (33.33\% response ketamine vs 0\% response placebo, Wilcoxon signed-rank test $z=2.24, p=0.025)$ and VAS (88.89\% response ketamine vs $52.94 \%$ response placebo, Wilcoxon signed-rank test $z=2.12, p=0.034)$. In conclusion, this proof-of-concept trial provides initial evidence that ketamine may be effective in reducing anxiety. Neuropsychopharmacology (2018) 43, 325-333; doi:I 0.1038/npp.20 17.194; published online II October 2017
\end{abstract}

\section{INTRODUCTION}

Social anxiety disorder (SAD) affects approximately $12 \%$ of adult Americans and is defined as a 'marked and persistent fear of one or more social situations,' causing impairment and distress (Kessler et al, 2005). SAD (also known as social phobia) typically negatively impacts academic achievement, work productivity, social relationships, and quality of life (Lipsitz and Schneier, 2000; Taylor et al, 2015; Taylor et al, 2016; Taylor et al, 2017a) and is associated with subsequent development of depression, alcoholism, and cardiovascular disease (Kessler, 2003; Kessler et al, 2005). Roughly one-third to one-half of patients with SAD do not experience significant clinical benefit from current evidence-based treatment for SAD such as pharmacotherapy with selective serotonin reuptake inhibitors (SSRI) or venlafaxine and cognitive behavioral therapy (CBT) (Kelly et al, 2014; RoyByrne et al, 2010; Taylor et al, 2015; Taylor et al, 2017b). Inadequate anxiety relief in patients with SAD is a source of

\footnotetext{
*Correspondence: Dr JH Taylor, Department of Psychiatry, University of Pennsylvania, Neuropsychiatry Section, 3400 Spruce Street, Gates Pavilion IOth Floor, Philadelphia, PA 19104, USA, Tel: + I 267536 9405, Fax: + 203907 2727, E-mail: taylorje@pennmedicine.upenn.edu Received 29 May 2017; revised 7 August 2017; accepted 22 August 2017; accepted article preview online 29 August 2017
}

substantial morbidity, distress, and decreases in quality of life. Novel pharmacological treatments are needed to improve outcomes in patients with SAD (Liebowitz et al, 2016; Taylor et al, 2015; Taylor et al, 2017b).

Converging lines of evidence from neuroimaging and pharmacological studies support the importance of glutamate abnormalities in the pathogenesis of SAD (Freitas-Ferrari et al, 2010). In a magnetic resonance spectroscopy study, an elevated glutamate to creatinine ratio was found in the anterior cingulate cortex of SAD patients when compared to healthy controls (Phan et al, 2005). Anterior cingulate glutamate/creatinine level was also positively correlated with severity of social anxiety symptoms (Phan et al, 2005). Others have documented elevated thalamic glutamine levels in patients with SAD (Pollack et al, 2008). Furthermore, preclinical rodent studies have established a strong link between glutamate regulation and anxiety (Domi et al, 2016; Donahue et al, 2014; Johnson et al, 2005; McGowan et al, 2017; Walker and Davis, 2002).

Ketamine is a potent antagonist of the $N$-methyl-Daspartate receptor, a major type of glutamate receptor in the brain (Gould et al, 2017). Ketamine is routinely used for anesthetic induction because of its dissociative properties. In addition to these dissociative properties, multiple controlled clinical studies indicate that ketamine effectively reduces 
symptoms of depression and is particularly effective in anxious depression (Ionescu et al, 2014). In controlled clinical studies ketamine has produced a rapid antidepressant effect in unipolar and bipolar depression (Abdallah et al, 2016; Berman et al, 2000; Carreno et al, 2015; Dwyer et al, 2017; Krystal et al, 2013; Maeng and Zarate, 2007; Milak et al, 2015; Murrough et al, 2013a; Murrough et al, 2013b; Niciu et al, 2014; Sanacora et al, 2016; Valentine et al, 2011; Zarate et al, 2006). Ketamine's antidepressant effects peak 1 day following infusion and typically dissipate 1-2 weeks after a single infusion (Kishimoto et al, 2016). Ketamine's antidepressant effect is observed long after ketamine has been metabolized and excreted from the body and after ketamine's sedative and dissociative effects have dissipated (Krystal et al, 2013).

Several clinical studies suggest that ketamine may also have significant anxiolytic effects. Adults with major depressive disorder given a single ketamine infusion have shown significant reductions in comorbid anxiety symptoms. One trial with 11 depressed subjects demonstrated a significant reduction in anxiety symptoms (Hamilton Anxiety Rating Scale (HAM-A)) following ketamine infusion (mean HAM-A score pretreatment $23.4 \pm 6.5$; mean HAM-A score after $230 \mathrm{~min} 14.3 \pm 7.8 ; \mathrm{t}(9)=3.39, p<0.01$, Effect Size $=1.4$ ) (Salvadore et $a l, 2009)$. Ketamine's anxiolytic effects have also been supported by placebo-controlled trials which demonstrated that the psychic anxiety item on the 21item HAM-D significantly improved after ketamine infusion (compared to saline); the psychic anxiety item was one of only four items to improve (Zarate et al, 2006). Randomized, placebo-controlled trials also suggest the possible benefit of ketamine for treating symptoms of obsessive-compulsive disorder (OCD) and post-traumatic stress disorder (Feder et al, 2014; Rodriguez et al, 2013). Given the positive results of these studies, we conducted a double-blind, randomized, placebo-controlled crossover study to investigate the efficacy and time course of action of intravenous ketamine in the treatment of SAD.

\section{MATERIALS AND METHODS}

\section{Overview}

We conducted a double-blind, randomized, placebocontrolled crossover trial in 18 adults with SAD and compared the effects of intravenous ketamine (dosed $0.5 \mathrm{mg} / \mathrm{kg}$ over $40 \mathrm{~min}$ ) on social anxiety symptoms compared to placebo (normal saline). A power analysis based on ketamine's antidepressant effects was used to determine the sample size of 18 (Murrough et al, 2013a; Zarate et al, 2006). All participants met Diagnostic and Statistical Manual of Mental Disorders, Fifth Edition (DSM-5) criteria for SAD. Ketamine and placebo infusions were administered in a random order with a 28-day washout period between infusions. That is, each participant received either ketamine or placebo infusion on Day 0; then on Day 28 the participant received whichever infusion they did not get on Day 0 . The study was conducted from 2014 to 2016 at Yale University in New Haven, CT. Randomization was conducted by the Yale Investigational Drug Service and kept separate from any other investigators involved in the trial. All procedures were approved by the Yale Human Investigation Committee.

\section{Inclusion Criteria and Recruitment}

Inclusion criteria were: (1) Male or female (post-menopausal, surgically sterile or negative pregnancy test at screening and agreement to utilize an established birth control including complete abstinence during the testing period) between the ages of 18 and 65 years old; (2) Meet DSM-5 criteria for SAD by structured clinical interview for DSM-5 (SCID) and have a Liebowitz Social Anxiety Score (LSAS) score $>60$ (Heimberg et al, 1999; Liebowitz, 1987; Mennin et al, 2002), which are typically seen in patients with at least moderate social anxiety. No other lifetime DSM-5 Axis I diagnoses by SCID were allowed, with the exception of comorbid anxiety and mood disorders; (3) Stable psychiatric medications. Patients must have had stable doses of all psychiatric medications for the month prior to treatment and have been on stable doses of SSRIs, SNRIs, and clomipramine for at least 2 months prior to study enrollment. Medications prescribed 'as needed' for anxiety (ie not taken regularly) were discontinued for the duration of the trial; (4) Not currently receiving cognitive behavioral therapy; (5) Medically and neurologically healthy. Individuals with stable medical problems and medications (eg, oral hypoglycemics) were included if their medications had not been adjusted in the month prior to entry; (6) No current substance use disorder diagnoses by SCID (excluding tobacco) and urine toxicology screen negative for drugs of abuse; (7) Able to provide written informed consent according to the Yale Human Investigation Committee guidelines.

Patients were recruited through clinicaltrials.gov, outreach to local anxiety peer support groups, and word of mouth. Participants were assessed for eligibility using a phone screen and a subsequent in-person medical and psychiatric evaluation.

\section{Assessments}

Assessments were conducted pre-infusion, 3-h post-infusion, and days $1,2,3,5,7,10$ and 14 post-infusion. The primary self-report outcome of the trial was self-rated anxiety on a visual analog scale (VAS) scored 0 ('not at all anxious')-100 ('as anxious as you could possibly be') (Aitken, 1969). Subjects also completed the State-Trait Anxiety Inventory State Subscale (STAI-S) (Barnes et al, 2002; Spielberger, 1983). The primary clinician-rated outcome was LSAS, scored $0-144$, to measure social anxiety at each assessment point. The LSAS (Heimberg et al, 1999; Mennin et al, 2002), VAS (Cella and Perry, 1986; Davey et al, 2007; Williams et al, 2010), and STAI-S (Spielberger, 1983) have demonstrated reliability and validity. LSAS scores $>60$ suggest moderate social anxiety and scores $>90$ suggest severe social anxiety (Heimberg et al, 1999). LSAS typically assesses symptoms during the prior week; however, the scale was modified so that participants were asked about their symptoms during the time since previous assessment. Blinded raters used the 17-item Hamilton Depression Rating Scale (HDRS-17) to measure depression (Hamilton, 1960). Blinded raters were not present for the $3 \mathrm{~h}$ following infusions and conducted assessments at a site different from the clinical unit where the infusion took place. Also, participants were instructed to not discuss any aspects of the infusion with blinded raters in order to avoid inadvertent unblinding by the patient 
discussing dissociative symptoms that frequently occurred during ketamine infusions. Separate raters present at the infusion conducted assessments regarding potential dissociative and psychotomimetic side-effects of the infusions including the Clinician Administered Dissociative States Scale (CADSS) (Bremner et al, 1998).

\section{Statistical Analyses}

All analyses were conducted in SAS version 9.4. All continuous outcomes (LSAS, VAS, HDRS-17, STAI-S) were sufficiently normally distributed as evidenced by the Shapiro-Wilk Test $(p$-values $=0.28,0.13,0.23,0.21)$. To investigate possible carryover effects in our trial, we used a paired $t$-test to compare the difference between baseline ratings in the first and second phase of the trial between different infusion order (ketamine first, placebo second or placebo first, ketamine second) for all continuous outcomes (LSAS, VAS, HDRS-17, STAI-S). When there exists a significant difference between baseline ratings based on the sequence of treatments, there is evidence of carryover effects in a crossover trial, and it is standard to analyze data from the first phase of the trial. When no significant carryover effects were present, we analyzed data from both phases of the crossover trial and present data from the first phase only as a sensitivity analysis. Carryover effects were demonstrated for the LSAS but not for other outcomes in this trial (VAS, HDRS-17, STAI-S), and thus data from the first phase of the trial were analyzed for the LSAS and its subscales.
Analysis of outcomes with carryover effects. When evidence of carryover effects was present, we restricted analysis to phase 1 data in the trial (up to day 14). We used SAS to construct a mixed-effects linear model with time and time-by-treatment interaction as included terms in the model. The restricted maximal likelihood method was used with an autoregressive covariance structure. We used this analysis for the LSAS as well as the analysis of LSAS subscale measures-specifically (1) the LSAS Fear and Avoidance factors and (2) the LSAS Social Anxiety and Social Avoidance and LSAS Performance Anxiety and Performance Avoidance factors (Heimberg et al, 1999).

Analysis of outcomes with no evidence of carryover effects. We used SAS to construct mixed-effects linear models for each continuous outcome with treatment, infusion order, time, and interactions between treatment and time as well as treatment and infusion order. Infusion order and interaction between treatment and infusion order were initially included in the models to additionally examine possible carryover effects. If these terms were both nonsignificant they were dropped from the final model as is standard in mixed-effects modeling of crossover trials. For all analyses, time, treatment, and infusion order were included as within-subject factors. The restricted maximal likelihood method was used with an autoregressive covariance structure. We used this method of analysis for the VAS-anxiety, HDRS-17, and STAI-S. As part of a sensitivity analysis, we additionally present results for all outcomes with data

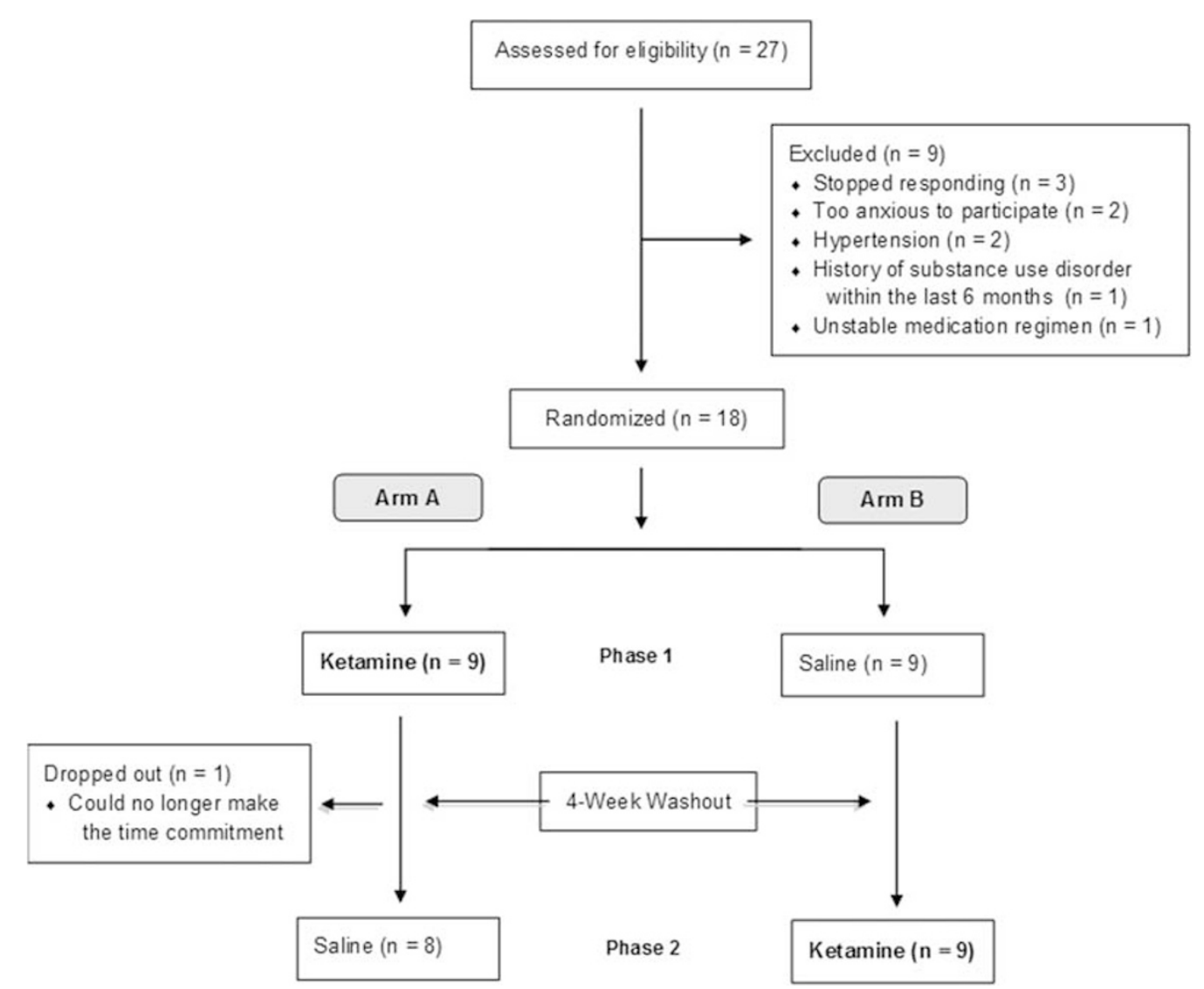

Figure I Patient recruitment and randomization. 
restricted to phase 1 of the trial given that some evidence of carryover effects was present in the trial. This analysis was identical to that outlined in the previous paragraph.

For all outcomes of continuous measures, we also present Cohen's $d$ with confidence intervals for least mean square estimates of treatment effects at each time point. For our primary outcomes, the VAS-anxiety and LSAS, we report data on all subjects (as well as secondary analyses involving STAI-S and CADSS). In our analysis of depression outcomes, only individuals with HDRS-17 $>15$ (suggestive of mild to moderate depression) (Zimmerman et al, 2013) at baseline were included.

We also examined the proportion of treatment responders using the Wilcoxon signed-rank test. Like prior studies, treatment response was defined by (1) a greater than $35 \%$ improvement in LSAS score (Bloch et al, 2012) based on the $\sim 34 \%$ LSAS reduction seen after SSRI treatment (Liebowitz et al, 2003) and (2) greater than 50\% improvement in VAS score from baseline at any point at least $24 \mathrm{~h}$ following infusion (Williams et al, 2010). For all primary and secondary outcomes alpha was set at 0.05 .

\section{RESULTS}

Figure 1 outlines subject flow through recruitment and enrollment. Of the 18 participants, 94\% $(n=17)$ completed both infusions. All patients tolerated the ketamine infusion without adverse outcome. One subject did not participate in the second infusion (placebo) because she needed to move out of state earlier than initially anticipated. Table 1 displays the characteristics of included subjects as a whole sample and stratified by infusion order. Table 2 displays individual patient demographic and clinical data.

\section{Carryover Effects}

There was evidence of significant carryover effects on the LSAS at 28 days following initial infusion but not with other outcome measures. Subjects receiving ketamine first had significantly lower baseline LSAS ratings prior to the start of the second treatment phase than subjects receiving placebo first (mean difference $=15.35, \mathrm{t}=2.84, \mathrm{df}=15, p=0.012$ ). Other primary outcomes (VAS: mean difference $=5.76$, $\mathrm{t}=0.58, \mathrm{df}=15, p=0.57$ ) and secondary outcomes (HDRS-17 : mean difference $=-0.15, \mathrm{t}=-0.08, \mathrm{df}=15, p=0.94$ and STAI-S: mean difference $=4.26, \mathrm{t}=1.14, \mathrm{df}=15, p=0.27$ ) did not demonstrate evidence of significant carryover effects.

\section{Blinded Clinical Ratings of Social Anxiety}

Ketamine demonstrated a significant benefit compared to saline infusion in reducing symptoms of social anxiety as measured by the LSAS (Time: $\mathrm{F}_{8,124}=3.0, p=0.004$ and Time $\times$ Treatment: $\left.F_{9,115}=2.6, p=0.01\right)$. Figure 2 depicts the change in LSAS ratings over the first 14 days following infusion in the ketamine as compared to the placebo group. Ketamine demonstrated a significant benefit at reducing LSAS scores at 2 (mean difference (diff) $=22.67 \pm 7.28$, effect size $(\mathrm{ES})=1.10, \quad \mathrm{~F}=4.9, \quad p=0.04), 5 \quad($ diff $=22.33 \pm 7.28$, $\mathrm{ES}=1.09, \mathrm{~F}=4.7, p=0.04)$ and 10 days (diff $=28.72 \pm 7.36$, $\mathrm{ES}=1.37, \mathrm{~F}=7.6, p=0.01)$ following infusion compared to placebo. Six of 18 subjects experienced a treatment response as indicated by a greater than $35 \%$ reduction on the LSAS after ketamine infusion compared to 0 of 17 subjects receiving placebo (Wilcoxon signed-rank test $z=2.24$, $p=0.025)$. Neither maximum CADSS rating after ketamine infusion $(\mathrm{F}=0.6, \mathrm{df}=1,31, p=0.44)$ nor age of onset of SAD $(\mathrm{F}=2.5, \mathrm{df}=1,15, p=0.14)$ significantly moderated the effects of ketamine on LSAS. Table 2 describes individual patient characteristics and ketamine LSAS response status.

Ketamine also demonstrated significant benefit compared to placebo in reducing symptoms on the LSAS Fear (Time: $\mathrm{F}_{8,120}=2.2, \quad p=0.03$ and Time $\times$ Treatment: $\mathrm{F}_{9,116}=2.3$, $p=0.02$ ) and LSAS Avoidance (Time: $\mathrm{F}_{8,122}=2.4, p=0.02$ and Time $\times$ Treatment: $\left.\mathrm{F}_{9,115}=2.2, p=0.03\right)$ subscales. Ketamine significantly reduced the LSAS Social Anxiety (Time: $\mathrm{F}_{8,122}=2.0, \quad p=0.06$ and Time $\times$ Treatment: $\mathrm{F}_{9,116}=3.1$, $p=0.002$ ) and Social Avoidance (Time: $\mathrm{F}_{8,120}=1.8, p=0.08$ and Time $\times$ Treatment: $F_{9,116}=2.3, p=0.02$ ) subscales but not the LSAS Performance Anxiety (Time: $\mathrm{F}_{8,121}=2.1$, $p=0.04$ and Time $\times$ Treatment: $\left.\mathrm{F}_{9,116}=1.5, p=0.16\right)$ and Performance Avoidance (Time: $\mathrm{F}_{8,122}=2.4, p=0.04$ and Time $\times$ Treatment: $\left.\quad \mathrm{F}_{9,115}=1.8, \quad p=0.08\right) \quad$ subscales. Supplementary Figures 1 and 2 depict the changes in each of the LSAS subscales after ketamine and placebo infusions.

\section{Self-Reported Ratings of Anxiety}

Ketamine did not demonstrate a significant difference from placebo in reducing anxiety symptoms on the VAS (Time: $\mathrm{F}_{10,141}=5.8, p<0.001$, Treatment: $\mathrm{F}_{1,27.4}=3.4, p=0.07$ and Time $\times$ Treatment: $\mathrm{F}_{10,141}=0.4, p=0.95$ ). Figure 3 depicts the effects of ketamine and placebo on VAS ratings of anxiety in the first 2 weeks following infusion. There was no time point when ketamine demonstrated a significant benefit compared to placebo on VAS ratings of anxiety. When analysis was restricted to the first phase of the trial in sensitivity analysis, ketamine still did not show a significant effect in reducing VAS measures of anxiety compared to placebo (Time: $\mathrm{F}_{10,141}=5.8, p<0.001$ and Time $\times$ Treatment: $\left.\mathrm{F}_{11,139}=0.6, p=0.80\right)$.

Ketamine was associated with a significantly greater likelihood of response on the VAS compared to placebo (Wilcoxon signed-rank test $z=2.12, p=0.034$ ). Sixteen of 18 $(88.89 \%)$ subjects experienced a treatment response as indicated by a greater than $50 \%$ reduction on the VAS after ketamine infusion compared to 9 of 17 (52.94\%) subjects receiving placebo. Neither maximum CADSS rating after ketamine infusion $(\mathrm{F}=0 ; \mathrm{df}=1,15.9, p=0.96)$ nor age of onset of SAD $(\mathrm{F}=0.28, \mathrm{df}=1,14.9, p=0.6)$ significantly moderated the effects of ketamine on VAS. Table 2 lists individual patient characteristics and ketamine VAS response status. Ketamine demonstrated a significant benefit on STAI-S ratings of anxiety compared to placebo (Time: $\mathrm{F}_{7,167}=5.4, p<0.001$, Treatment: $\mathrm{F}_{1,47}=8.2, p=0.006$ and Time $\times$ Treatment: $\left.F_{7,167}=1.6, p=0.12\right)$. Ketamine demonstrated a significant benefit compared to placebo at 1 $($ diff $=7.76 \pm 2.30, \mathrm{ES}=0.83, \mathrm{~F}=5.7, p=0.02), 7(\mathrm{diff}=8.53$ $\pm 2.28, \mathrm{ES}=0.92, \mathrm{~F}=7.0, p=0.01)$ and 10 days $(\mathrm{diff}=8.39$ $\pm 2.64, \mathrm{ES}=0.78, \mathrm{~F}=5.0, p=0.03$ ) following infusion. In sensitivity analysis, when analysis was restricted to the first phase of the trial, ketamine also demonstrated significant benefit compared to placebo in reducing anxiety symptoms on the STAI-S (Time: $\mathrm{F}_{7,78.4}=4.2, p<0.001$ and Time $\times$ 
Ketamine for social anxiety

$\mathrm{H}$ Taylor et al

Table I Pretreatment Sample Characteristics Stratified by Infusion Order

\begin{tabular}{|c|c|c|c|c|c|c|}
\hline & Overall & & Placebo first & & Ketamine first & \\
\hline Characteristic & $N=18$ & & $n=9$ & & $n=9$ & \\
\hline Continuous variables & Mean & Std Dev & Mean & Std Dev & Mean & Std Dev \\
\hline Age (years) & 29.72 & 11.05 & 28.67 & 8.66 & 30.78 & 13.50 \\
\hline LSAS & 90.67 & 16.94 & 87.44 & 14.53 & 93.89 & 19.37 \\
\hline VAS-Anxiety & 50.00 & 18.94 & 57.78 & 19.70 & 47.22 & 18.89 \\
\hline HDRSI7 & 17.56 & 7.78 & 17.89 & 8.30 & 17.22 & 7.71 \\
\hline CADSS & 1.44 & 2.23 & 2.56 & 2.60 & 0.33 & 1.00 \\
\hline Categorical variables & $n$ & $\%$ & $n$ & $\%$ & $n$ & $\%$ \\
\hline Female & 7 & 38.89 & 5 & 55.56 & 2 & 22.22 \\
\hline \multicolumn{7}{|l|}{ Race/Ethnicity } \\
\hline Non-Hispanic White & 14 & 77.78 & 6 & 66.67 & 8 & 88.89 \\
\hline Non-Hispanic Asian & 2 & | I.I | & 2 & 22.22 & 0 & 0 \\
\hline Hispanic & 2 & $|1.1|$ & । & 11.11 & 1 & $|1.1|$ \\
\hline \multicolumn{7}{|l|}{ GAD } \\
\hline Current & 9 & 50.00 & 4 & 44.44 & 5 & 55.55 \\
\hline Prior & 2 & $|1.1|$ & 2 & 22.22 & 0 & 0 \\
\hline \multicolumn{7}{|l|}{ Specific phobia } \\
\hline Current & 2 & $|1.1|$ & 0 & 0 & 2 & 22.22 \\
\hline Prior & 0 & 0 & 0 & 0 & 0 & 0 \\
\hline \multicolumn{7}{|l|}{ Panic disorder } \\
\hline Current & I & 5.56 & 0 & 0 & 1 & $|1.1|$ \\
\hline Prior & 2 & $|1.1|$ & I & $\mid 1.11$ & 1 & 11.11 \\
\hline \multicolumn{7}{|l|}{ MDD } \\
\hline Current & 3 & 16.67 & 2 & 22.22 & 1 & $\mid 1.11$ \\
\hline Prior & 2 & | I.I | & 0 & 0 & 2 & 22.22 \\
\hline \multicolumn{7}{|l|}{ Persistent depressive disorder } \\
\hline Current & 5 & 27.78 & 3 & 33.33 & 2 & 22.22 \\
\hline Prior & 2 & | I.| | & 0 & 0 & 2 & 22.22 \\
\hline \multicolumn{7}{|l|}{ SSRI/SNRI } \\
\hline Current & 5 & 27.78 & 3 & 33.33 & 2 & 22.22 \\
\hline Prior & 12 & 66.67 & 5 & 55.56 & 7 & 77.78 \\
\hline \multicolumn{7}{|l|}{ Benzodiazepine } \\
\hline Current & 2 & $|1.1|$ & 0 & 0 & 2 & 22.22 \\
\hline Prior & 3 & 16.67 & 2 & 22.22 & 1 & $\mid 1.11$ \\
\hline Prior CBT & 4 & 22.22 & 0 & 0 & 4 & 44.44 \\
\hline Prior psychotherapy (excluding CBT) & 6 & 33.33 & 4 & 44.44 & 2 & 22.22 \\
\hline
\end{tabular}

Abbreviations: CADSS, Clinician Administered Dissociative States Scale; CBT, cognitive behavioral therapy; GAD, generalized anxiety disorder; HDRS I7, I7-item Hamilton Depression Rating Scale; LSAS, Liebowitz Social Anxiety Scale; MDD, major depressive disorder, SSRI/SNRI, selective serotonin reuptake inhibitor/serotoninnorepinephrine reuptake inhibitor; VAS, Visual Analog Scale. 


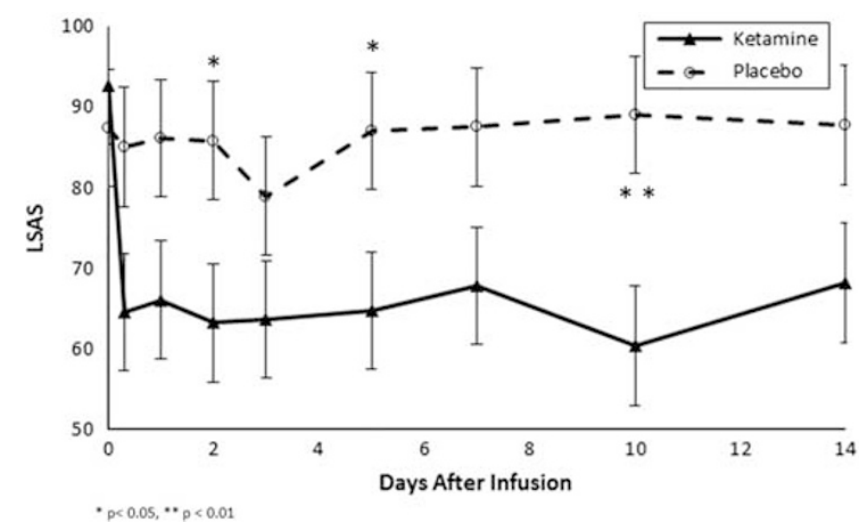

Figure 2 Effects of ketamine and placebo on Liebowitz Social Anxiety Scale (LSAS) score.

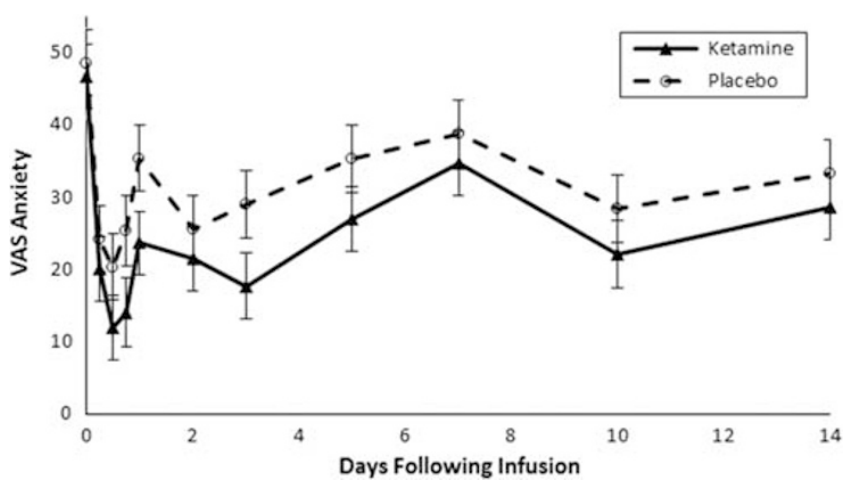

Figure 3 Effects of ketamine and placebo on Visual Analog Scale-Anxiety (VAS) score.

Treatment: $\left.\mathrm{F}_{8,79.9}=2.8, p=0.008\right)$. Supplementary Figure 3 depicts the changes in STAI-S ratings of anxiety in the first 2 weeks following infusion after both ketamine and placebo infusions.

\section{Depression Severity}

Ketamine did not significantly reduce comorbid depressive symptoms in the 12 subjects with comorbid depressive symptoms at baseline (Baseline HDRS17 mean $=22, \mathrm{SD}=5$, range $=16-30$; severe depression is typically defined as HDRS17 $\geqslant 24$ ) (Zimmerman et al, 2013). There were no significant differences in reducing depressive symptoms when results were examined in both phases of the crossover trial (Time: $\mathrm{F}_{8,56.9}=2.0, p=0.07$, Treatment: $\mathrm{F}_{1,12.4}=1.5$, $p=0.24$ and Time $\times$ Treatment: $\left.\mathrm{F}_{8,56.9}=1.0, p=0.49\right)$ or restricted to phase 1 (Time: $F_{8,56.9}=2.0, p=0.07$ and Time $\times$ Treatment: $\left.F_{9,54.6}=0.9, p=0.52\right)$. Supplementary Figure 4 depicts the changes in HDRS-17 ratings of depression in the first 2 weeks following infusion after both ketamine and placebo infusions.

\section{Safety and Tolerability}

Ketamine was safe and generally well tolerated by all subjects, and all ketamine infusions were completed. The most common side effects of ketamine were paresthesias and numbness $(n=9)$, feeling disconnected from reality $(n=7)$, vision changes $(n=6)$, feeling confused/difficulties thinking $(n=6)$, dizziness

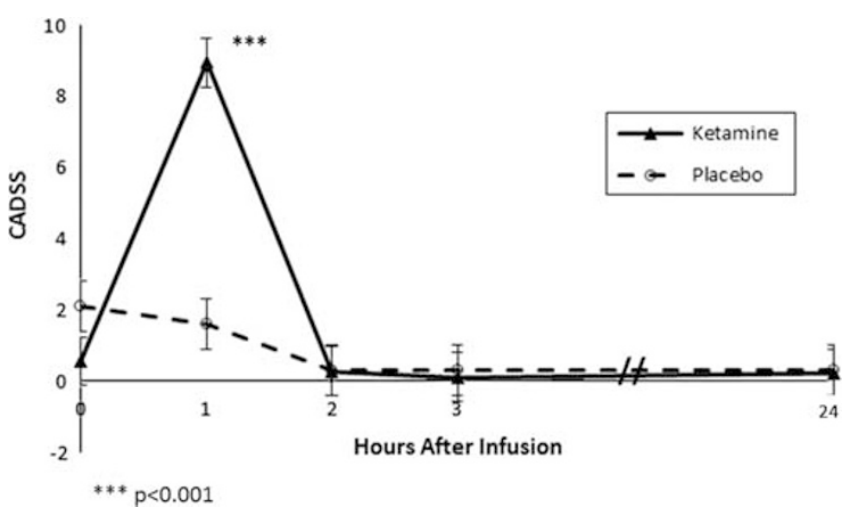

Figure 4 Effects of ketamine and placebo on Clinician Administered Dissociative States Scale (CADSS) score.

$(n=6)$, distorted sense of time $(n=4)$, tachycardia $>100$ beats per minute $(n=4$, max heart rate 120$)$, diastolic hypertension $>90 \mathrm{~mm} \mathrm{Hg}(n=3$, max diastolic blood pressure 106), bouts of laughter $(n=3)$, distorted hearing $(n=3)$, visual hallucinations $(n=3)$, nausea $(n=3)$, lightheadedness $(n=3)$, sense of floating $(n=2)$, body feeling heavy $(n=2)$, increased anxiety during infusion $(n=2)$, systolic hypertension $>160 \mathrm{~mm} \mathrm{Hg} \quad(n=2$, max systolic blood pressure 184) and diastolic hypotension $<60 \mathrm{~mm} \mathrm{Hg}(\mathrm{n}=2$, minimum diastolic blood pressure 49). All symptoms resolved within $2 \mathrm{~h}$ of infusion completion. Ketamine demonstrated significantly greater dissociative side effects compared to placebo on the CADSS (Time: $\mathrm{F}_{4,131}=19.5$, $p<0.001$, Treatment: $\mathrm{F}_{1,73}=6.3, p=0.01$ and Time $\times$ Treatment: $\left.F_{4,131}=13.1, p<0.01\right)$ that peaked during infusion ( $1 \mathrm{~h}$ : difference $=7.25 \pm 0.70, \quad \mathrm{ES}=2.53, \mathrm{~F}=56.1, \quad p<0.001) \quad$ and dissipated within $2 \mathrm{~h}$ following infusion $(2 \mathrm{~h}$ : difference $=0.02$ $\pm 0.70, \mathrm{ES}=0, \mathrm{~F}=0, p=0.99$ ). Figure 4 depicts the change in CADSS ratings in subjects treated with ketamine and placebo.

\section{DISCUSSION}

Ketamine resulted in a significantly greater reduction in anxiety when compared to placebo as assessed by blinded ratings on the LSAS but not on self-reported VAS-anxiety measures. Ketamine also demonstrated significantly greater number of treatment responders as assessed by both LSAS and VAS ratings. Our findings provide evidence for the potential use of ketamine-like compounds for reducing symptoms in SAD. To our knowledge, this is the first placebo-controlled study to investigate ketamine's efficacy in patients with a DSM-5 anxiety disorder.

The results of the study are consistent with previous work suggesting that ketamine has anxiolytic effects in patients with major depression (Salvadore et al, 2009; Zarate et al, 2006). Prior work has also found that ketamine reduced OCD symptoms (Bloch et al, 2012; Rodriguez et al, 2013). For example, Rodriguez et al, 2013 found post-infusion ratings were lower 1 week post-infusion on the Yale-Brown Obsessive Compulsive Scale (YBOCS) (Rodriguez et al, 2013). Furthermore, a 2017 study of 12 adults with generalized anxiety disorder and/or social anxiety found ketamine reduced anxiety symptoms; however, the study was open label and there was no placebo control (Glue et al, 2017). Of note, in our study the overall sample continued to have moderate social anxiety symptoms post-ketamine despite 
reductions in symptoms. Two of the six ketamine responders, as measured by the LSAS, continued to have moderate social anxiety symptoms $24 \mathrm{~h}$ after ketamine infusion.

Additionally, in our study ketamine did not significantly improve depressive symptoms. Several studies have demonstrated the efficacy of ketamine for treatment-resistant depression (Zarate et al, 2006). The lack of efficacy in our trial is likely due the fact that in our study most patients had mild to moderate depression as opposed to the more severe treatment-resistant major depression studied in ketamine clinical trials (Murrough et al, 2013a; Murrough et al, 2013b; Zarate et al, 2006). In fact, only three patients in this trial met criteria for current major depressive disorder. Furthermore, our study was under-powered to detect a change in depression ratings. More research is needed to determine whether ketamine is effective in moderate depression.

A significant limitation of our study was that 17 of 18 patients correctly identified when they received ketamine, suggesting that the use of saline as a placebo control for ketamine led to inadequate blinding. This inadequate blinding was not unique to our study and has been quite typical in previous saline-controlled ketamine studies. This functional unblinding may affect self-report measures (eg VAS) as well as lead to possible reporting bias even on ratings conducted by blinded raters (eg LSAS, HDRS-17). Further larger, randomized, midazolam-controlled trials (Murrough et al, 2013a) should be performed to confirm the benefits of ketamine for SAD as well as debilitating anxiety in general. A midazolam-controlled trial would not fully eliminate the issue of functional unblinding with ketamine but may reduce the issue somewhat. We would suggest that these future trials should (1) employ a parallel rather than crossover design as there seems to be more durable effects of ketamine on anxiety as compared to depression (leading to an increased likelihood of carryover effects) and an active control, even though blinding with active controls like midazolam is suboptimal (and giving subjects both medications exacerbates this issue); (2) use blinded, clinical-ratings of anxiety rather than the VAS as these gestalt ratings, even though theoretically more sensitive to change, appear particularly sensitive to momentary or situational anxiety; and (3) consider additional physiological measures of anxiety (eg skin conductance) to capture the effects of ketamine.

Future studies should also explore several other aspects of administration including the optimal dosing of ketamine for anxiety and the effects of repeated ketamine dosing on anxiety symptoms (Murrough et al, 2013b). Future studies should also include genotyping, specifically for the brainderived neurotrophic factor (BDNF) allele at rs6265 (Ribeiro et al, 2007) because the Val/Val BDNF allele at rs6265 has been associated with greater ketamine antidepressant effects relative to the effects seen in Met carriers (Laje et al, 2012).

Our trial is meant to demonstrate proof-of-concept for the potential use of ketamine-like compounds for reducing symptoms of anxiety. Overall, ketamine appeared to be effective in alleviating social anxiety symptoms over the short term. The overall improvement of anxiety symptoms after

Table 2 Individual Participant Characteristics and Ketamine Response

\begin{tabular}{|c|c|c|c|c|c|c|c|c|}
\hline $\begin{array}{l}\text { Agel } \\
\text { Sexl } \\
\text { Race }\end{array}$ & $\begin{array}{c}\text { Age of SAD } \\
\text { onset } \\
\text { (years) }\end{array}$ & $\begin{array}{l}\text { Current neuropsychotropic } \\
\text { medications }\end{array}$ & $\begin{array}{l}\text { Infusion } \\
\text { order (first } \\
\text { infusion) }\end{array}$ & $\begin{array}{l}\text { Ketamine } \\
\text { responder on } \\
\text { LSAS and/or VAS }\end{array}$ & $\begin{array}{l}\text { LSAS prel } \\
\text { post } \\
\text { ketamine }\end{array}$ & $\begin{array}{l}\text { VAS pre/post } \\
\text { ketamine }\end{array}$ & $\begin{array}{l}\text { HDRSI7 prel } \\
\text { post } \\
\text { ketamine }\end{array}$ & $\begin{array}{l}\text { Max CADSS } \\
\text { ketaminel } \\
\text { placebo }\end{array}$ \\
\hline $25 / F / C$ & 14 & NONE & $P$ & VAS & $85 / 86$ & $30 / 30$ & $21 / 7$ & $3 / 0$ \\
\hline $25 / M / C$ & 4 & NONE & K & Non-responder & $94 / 94$ & $35 / 20$ & $26 / 22$ & $0 / 0$ \\
\hline $30 / \mathrm{M} / \mathrm{C}$ & 6 & Alprazolam, gabapentin & K & VAS & $84 / 92$ & $25 / 25$ & $13 / 8$ & $9 / 0$ \\
\hline $30 / F / C$ & 18 & Paroxetine & $P$ & VAS & $70 / 7 \mid$ & $65 / 0$ & $5 / 0$ & $22 / 0$ \\
\hline $32 / \mathrm{M} / \mathrm{A}$ & 13 & Bupropion & $P$ & VAS & $96 / 96$ & $90 / 65$ & $28 / 24$ & $5 / 3$ \\
\hline 24/F/C & 13 & NONE & $P$ & LSAS & $52 / 53$ & $55 / 55$ & $22 / 14$ & $16 / 10$ \\
\hline I8/M/C & 11 & $\begin{array}{l}\text { Lisdexamfetamine, sertraline, } \\
\text { amitriptyline }\end{array}$ & $P$ & VAS & $91 / 76$ & $30 / 15$ & $21 / 10$ & $8 / 0$ \\
\hline $44 / F / C$ & 5 & $\begin{array}{l}\text { Amphetamine/ } \\
\text { dextroamphetamine mixed salts, } \\
\text { clonazepam }\end{array}$ & K & LSAS+VAS & $89 / 59$ & $65 / 5$ & $25 / 9$ & $0 / 0$ \\
\hline $48 / F / C$ & 12 & NONE & $P$ & VAS & $81 / 67$ & $50 / 10$ & $16 / 5$ & $9 / 0$ \\
\hline $24 / M / C$ & 14 & NONE & K & LSAS+VAS & $79 / 75$ & $25 / 10$ & $1 \mid / 5$ & $8 / 0$ \\
\hline $23 / F / C$ & 19 & NONE & P & VAS & $84 / 85$ & $35 / 60$ & $5 / 3$ & $12 / 6$ \\
\hline I8/M/C & 13 & NONE & K & LSAS+VAS & $112 / 63$ & $50 / 20$ & $6 / 6$ & $27 / 0$ \\
\hline $24 / F / C$ & 5 & NONE & K & VAS & $94 / 66$ & $30 / 10$ & $12 / 0$ & $5 /-$ \\
\hline
\end{tabular}

Abbreviations: A, Asian; C, Caucasian; CADSS, Clinician Administered Dissociative States Scale; F, Female; HDRS I7, I7-item Hamilton Depression Rating Scale; K, Ketamine; LSAS, Leibowitz Social Anxiety Scale; M, Male; P, Placebo; SAD, social anxiety disorder; VAS, Visual Analog Scale for Anxiety.

This table displays the individual characteristics for the participants in the trial listed in order of trial enrollment. Pre/post ketamine and saline results are indicative of scores received on Day 0 prior to the infusion and on Day I (24 h after the infusion), respectively. Response could occur at any point during the I4 days following infusion (ie some patients responded after Day I). 
ketamine infusion seemed possibly more modest in scale (effect size varied from 0.2 to 0.6 on the VAS to $0.74-1.38$ on the LSAS during the first 2 weeks following infusion) but perhaps more durable than that observed in previous depression studies. The LSAS measures demonstrated significant carryover effects 28 days following infusion with an effect size $=0.93$ at 14 days. A possible explanation for the carryover effects of ketamine is that when a subject's social anxiety was reduced, the subject participated in more social activities. Increased exposure to social activities is a treatment for SAD (eg CBT) (Peris et al, 2015; Roy-Byrne et al, 2010; Taylor et al, 2015; Taylor et al, 2017b) and may have maintained ketamine's anxiolytic effects. Several participants reported increased social engagement in the days following ketamine infusion; however, we did not systematically track social exposure, and further research is needed to substantiate this hypothesis. These findings should not be used as definitive evidence for the use of ketamine as a long-term treatment for anxiety as this is a small, proof-ofconcept study that did not show significant benefit on all outcome measures. Several ketamine-like glutamate modulators, including AXS-05 and esketamine, are under investigation by pharmaceutical companies and in Clinical Trial phases II and III for depression (Liu et al, 2016; Murrough, 2016). Our findings suggest ketamine-like compounds may also be effective in SAD and could be investigated for other anxiety disorders.

\section{FUNDING AND DISCLOSURE}

Dr Bloch receives research support from Biohaven Pharmaceuticals and Therapix Biosciences, but neither provided support for the current trial. No other authors have potential conflicts of interest.

\section{ACKNOWLEDGMENTS}

The authors gratefully acknowledge support from the Robert E. Leet and Clara Guthrie Patterson Trust (JHT, AL-W, MHB), National Institutes of Health/National Institute of Mental Health (NIH/NIMH, 5T32MH018268, 5T32MH19961, 5T32MH019112, JHT; 1K23MH091240, $\mathrm{MHB}$ ) and NARSAD (MHB). Additionally, the LSAS is a copyrighted scale, and we thank Michael Lebowitz, MD for allowing us to use the scale free of charge. ClinicalTrials.gov Identifier: NCT02083926

\section{REFERENCES}

Abdallah CG, Averill LA, Collins KA, Geha P, Schwartz J, Averill C et al (2016). Ketamine treatment and global brain connectivity in major depression. Neuropsychopharmacology 42: 1210-1219.

Aitken RC (1969). Measurement of feelings using visual analogue scales. Proc R Soc Med 62: 989.

Barnes L, Harp D, Jung WS (2002). Reliability generalization of scores on the Spielberger state-trait anxiety inventory. Educ Psychol Meas 62: 603-618.

Berman RM, Cappiello A, Anand A, Oren DA, Heninger GR, Charney DS et al (2000). Antidepressant effects of ketamine in depressed patients. Biol Psychiatry 47: 351-354.

Bloch MH, Wasylink S, Landeros-Weisenberger A, Panza KE, Billingslea E, Leckman JF et al (2012). Effects of ketamine in treatment-refractory obsessive-compulsive disorder. Biol Psychiatry 72: 964-970.

Bremner JD, Krystal JH, Putnam FW, Southwick SM, Marmar C, Charney DS et al (1998). Measurement of dissociative states with the Clinician-Administered Dissociative States Scale (CADSS). J Trauma Stress 11: 125-136.

Carreno F, Donegan J, Boley A, Shah A, DeGuzman M, Frazer A et al (2015). Activation of a ventral hippocampus-medial prefrontal cortex pathway is both necessary and sufficient for an antidepressant response to ketamine. Mol Psychiatry 21: 1298-1308.

Cella DF, Perry SW (1986). Reliability and concurrent validity of three visual-analogue mood scales. Psychol Rep 59: 827-833.

Davey HM, Barratt AL, Butow PN, Deeks JJ (2007). A one-item question with a Likert or Visual Analog Scale adequately measured current anxiety. J Clin Epidemiol 60: 356-360.

Domi E, Uhrig S, Soverchia L, Spanagel R, Hansson AC, Barbier E et al (2016). Genetic deletion of neuronal PPAR $\gamma$ enhances the emotional response to acute stress and exacerbates anxiety: an effect reversed by rescue of amygdala PPAR $\gamma$ function. J Neurosci 36: 12611-12623.

Donahue RJ, Muschamp JW, Russo SJ, Nestler EJ, Carlezon WA (2014). Effects of striatal $\Delta$ FosB overexpression and ketamine on social defeat stress-induced anhedonia in mice. Biol Psychiatry 76: 550-558.

Dwyer JB, Beyer C, Wilkinson ST, Ostroff RB, Qayyum Z, Bloch $\mathrm{MH}$ (2017). Ketamine as a treatment for adolescent depression: a case report. J Am Acad Child Adolescent Psychiatry 56: 352-354.

Feder A, Parides MK, Murrough JW, Perez AM, Morgan JE, Saxena $S$ et al (2014). Efficacy of intravenous ketamine for treatment of chronic posttraumatic stress disorder: a randomized clinical trial. JAMA Psychiatry 71: 681-688.

Freitas-Ferrari MC, Hallak JE, Trzesniak C, Santos Filho A, Machado-de-Sousa JP, Chagas MHN et al (2010). Neuroimaging in social anxiety disorder: a systematic review of the literature. Prog Neuropsychopharmacol Biol Psychiatry 34: 565-580.

Glue P, Medlicott NJ, Harland S, Neehoff S, Anderson-Fahey B, Le Nedelec $M$ et al (2017). Ketamine's dose-related effects on anxiety symptoms in patients with treatment refractory anxiety disorders. J Psychopharmacol 0269881117705089. doi:10.1177/0269881117705089; e-pub ahead of print.

Gould TD, Zanos P, Zarate CA (2017). Ketamine mechanism of action: separating the wheat from the chaff. Neuropsychopharmacology 42: 368-369.

Hamilton M (1960). A rating scale for depression. I Neurol Neurosurg Psychiatry 23: 56-62.

Heimberg RG, Horner K, Juster H, Safren S, Brown E, Schneier F et al (1999). Psychometric properties of the Liebowitz social anxiety scale. Psychol Med 29: 199-212.

Ionescu DF, Luckenbaugh DA, Niciu MJ, Richards EM, Slonena EE, Voort JLV et al (2014). Effect of baseline anxious depression on initial and sustained antidepressant response to ketamine. J clin psychiatry 75: 932-938.

Johnson MP, Barda D, Britton TC, Emkey R, Hornback WJ, Jagdmann GE et al (2005). Metabotropic glutamate 2 receptor potentiators: receptor modulation, frequency-dependent synaptic activity, and efficacy in preclinical anxiety and psychosis model (s). Psychopharmacology (Berl) 179: 271-283.

Kelly JM, Jakubovski E, Bloch MH (2014). Prognostic subgroups for remission and response in the Coordinated Anxiety Learning and Management (CALM) trial. J clin psychiatry 76: 267-278.

Kessler R (2003). The impairments caused by social phobia in the general population: implications for intervention. Acta Psychiatr Scand 108: 19-27.

Kessler RC, Chiu WT, Demler O, Walters EE (2005). Prevalence, severity, and comorbidity of 12-month DSM-IV disorders in the National Comorbidity Survey Replication. Arch gen psychiatr 62: 617-627.

Kishimoto T, Chawla JM, Hagi K, Zarate CA, Kane JM, Bauer M et al (2016). Single-dose infusion ketamine and non-ketamine 
N-methyl-d-aspartate receptor antagonists for unipolar and bipolar depression: a meta-analysis of efficacy, safety and time trajectories. Psychol Med 46: 1459-1472.

Krystal JH, Sanacora G, Duman RS (2013). Rapid-acting glutamatergic antidepressants: the path to ketamine and beyond. Biol Psychiatry 73: 1133-1141.

Laje G, Lally N, Mathews D, Brutsche N, Chemerinski A, Akula N et al (2012). Brain-derived neurotrophic factor Val66Met polymorphism and antidepressant efficacy of ketamine in depressed patients. Biol Psychiatry 72: e27.

Liebowitz MR (1987). Social phobia. Mod Prob Pharmacopsychiatry 22: 141-173.

Liebowitz MR, DeMartinis NA, Weihs K, Londborg PD, Smith WT, Chung $\mathrm{H}$ et al (2003). Efficacy of sertraline in severe generalized social anxiety disorder: results of a double-blind, placebocontrolled study. J Clin Psychiatry 64: 785-792.

Liebowitz MR, Hanover R, Draine A, Lemming R, Careri J, Monti L (2016). Effect of as-needed use of intranasal PH94B on social and performance anxiety in individuals with social anxiety disorder. Depress Anxiety 33: 1081-1089.

Lipsitz JD, Schneier FR (2000). Social phobia. Pharmacoeconomics 18: $23-32$.

Liu R-J, Duman C, Kato T, Hare B, Lopresto D, Bang E et al (2016). GLYX-13 produces rapid antidepressant responses with key synaptic and behavioral effects distinct from ketamine. Neuropsychopharmacology 42: 1231-1242.

Maeng S, Zarate CA Jr (2007). The role of glutamate in mood disorders: results from the ketamine in major depression study and the presumed cellular mechanism underlying its antidepressant effects. Curr psychiatry rep 9: 467-474.

McGowan JC, LaGamma CT, Lim SC, Tsitsiklis M, Neria Y, Brachman RA et al (2017). Prophylactic ketamine attenuates learned fear. Neuropsychopharmacology 42: 1577-1589.

Mennin DS, Fresco DM, Heimberg RG, Schneier FR, Davies SO, Liebowitz MR (2002). Screening for social anxiety disorder in the clinical setting: using the Liebowitz Social Anxiety Scale. J Anxiety Disord 16: 661-673.

Milak M, Proper C, Mulhern S, Parter A, Kegeles L, Ogden R et al (2015). A pilot in vivo proton magnetic resonance spectroscopy study of amino acid neurotransmitter response to ketamine treatment of major depressive disorder. Mol Psychiatry 21: 320-327.

Murrough JW (2016). Ketamine for depression: an update. Biol Psychiatry 80: 416-418.

Murrough JW, Iosifescu DV, Chang LC, Al Jurdi RK, Green CE, Perez AM et al (2013a). Antidepressant efficacy of ketamine in treatment-resistant major depression: a two-site randomized controlled trial. Am J Psychiatry 170: 1134-1142.

Murrough JW, Perez AM, Pillemer S, Stern J, Parides MK, aan het Rot $\mathrm{M}$ et al (2013b). Rapid and longer-term antidepressant effects of repeated ketamine infusions in treatment-resistant major depression. Biol Psychiatry 74: 250-256.

Niciu MJ, Henter ID, Luckenbaugh DA, Zarate CA Jr, Charney DS (2014). Glutamate receptor antagonists as fast-acting therapeutic alternatives for the treatment of depression: ketamine and other compounds. Annu Rev Pharmacol Toxicol 54: 119-139.

Peris TS, Compton SN, Kendall PC, Birmaher B, Sherrill J, March J et al (2015). Trajectories of change in youth anxiety during cognitive-behavior therapy. J Consult Clin Psychol 83: 239.

Phan KL, Fitzgerald DA, Cortese BM, Seraji-Bozorgzad N, Tancer ME, Moore GJ (2005). Anterior cingulate neurochemistry in social anxiety disorder: $1 \mathrm{H}-\mathrm{MRS}$ at 4 Tesla. Neuroreport 16: $183-186$.
Pollack MH, Jensen JE, Simon NM, Kaufman RE, Renshaw PF (2008). High-field MRS study of GABA, glutamate and glutamine in social anxiety disorder: response to treatment with levetiracetam. Prog Neuropsychopharmacol Biol Psychiatry 32: 739-743.

Ribeiro L, Busnello JV, Cantor RM, Whelan F, Whittaker P, Deloukas P et al (2007). The brain-derived neurotrophic factor rs6265 (Val66Met) polymorphism and depression in MexicanAmericans. Neuroreport 18: 1291.

Rodriguez CI, Kegeles LS, Levinson A, Feng T, Marcus SM, Vermes D et al (2013). Randomized controlled crossover trial of ketamine in obsessive-compulsive disorder: proof-of-concept. Neuropsychopharmacology 38: 2475-2483.

Roy-Byrne P, Craske MG, Sullivan G, Rose RD, Edlund MJ, Lang AJ et al (2010). Delivery of evidence-based treatment for multiple anxiety disorders in primary care: a randomized controlled trial. Jama 303: 1921-1928.

Salvadore G, Cornwell BR, Colon-Rosario V, Coppola R, Grillon C, Zarate CA et al (2009). Increased anterior cingulate cortical activity in response to fearful faces: a neurophysiological biomarker that predicts rapid antidepressant response to ketamine. Biol Psychiatry 65: 289-295.

Sanacora G, Heimer H, Hartman D, Mathew S, Frye M, Nemeroff C et al (2016). Balancing the promise and risks of ketamine treatment for mood disorders. Neuropsychopharmacology 42: 1179-1181.

Spielberger CD. Manual for the State-Trait Anxiety Inventory STAI (form Y)('self-evaluation questionnaire'). Mind Garden: Palo Alto, CA, 1983.

Taylor JH, Jakubovski E, Bloch MH (2015). Predictors of anxiety recurrence in the Coordinated Anxiety Learning and Management (CALM) trial. J Psychiatr Res 65: 154-165.

Taylor JH, Lebowitz ER, Silverman WK. Anxiety Disorders. In A. Martin, M.H. Bloch, F.R. Volkmar (eds.), Lewis's child and adolescent psychiatry: A comprehensive textbook. 5th edition. Wolters Kluwer: Philadelphia, PA, 2017a, pp. 509-518.

Taylor JH, Lebowitz ER, Jakubovski E, Coughlin CG, Silverman WK, Bloch MH (2017b). Monotherapy insufficient in severe anxiety? Predictors and moderators in the Child/Adolescent Anxiety Multimodal Study. J Clin Child Adolesc Psychol in press.

Taylor JH, Xu Y, Li F, Shaw M, Dziura J, Caprio S et al (2016). Psychosocial predictors and moderators of weight management programme outcomes in ethnically diverse obese youth. Pediatr Obes. doi:10.1111/ijpo.12165.

Valentine GW, Mason GF, Gomez R, Fasula M, Watzl J, Pittman B et al (2011). The antidepressant effect of ketamine is not associated with changes in occipital amino acid neurotransmitter content as measured by [1 H]-MRS. Psychiatry Res Neuroimag 191: 122-127.

Walker DL, Davis M (2002). The role of amygdala glutamate receptors in fear learning, fear-potentiated startle, and extinction. Pharmacol Biochem Behav 71: 379-392.

Williams VS, Morlock RJ, Feltner D (2010). Psychometric evaluation of a visual analog scale for the assessment of anxiety. Health qual life outcomes 8: 57.

Zarate CA, Singh JB, Carlson PJ, Brutsche NE, Ameli R, Luckenbaugh DA et al (2006). A randomized trial of an $\mathrm{N}$-methyl-D-aspartate antagonist in treatment-resistant major depression. Arch Gen Psychiatry 63: 856-864.

Zimmerman M, Martinez JH, Young D, Chelminski I, Dalrymple K (2013). Severity classification on the Hamilton depression rating scale. J Affect Disord 150: 384-388.

Supplementary Information accompanies the paper on the Neuropsychopharmacology website (http://www.nature.com/npp) 